\title{
EDUCAÇÃO DE ADULTOS: \\ NADA PODE FICAR PARA TRÁS!
}

\author{
Bravo Nico \\ (Universidade de Évora)
}

As palavras que se seguem nasceram no Alentejo, essa incontornável circunstância natural, social e humana que determina, de forma tranquila, mas incontornável, o pensamento e a ação daqueles que aí existem. O Alentejo, atualmente classificado como território do interior e de baixa densidade, é uma região em que há pouca gente: gente mais velha do que nova; gente, por vezes, afastada dos acessos ao exercício dos respetivos direitos e deveres de cidadania; gente, quase sempre, esquecida pelas políticas públicas; gente, muitas vezes, entregue a si própria e à sua resiliência.

A Educação dos Adultos no Alentejo - e na generalidade dos denominados territórios do interior - é, em grande medida, a educação que as suas gentes conseguiram construir, para se construírem a elas próprias. Quase sempre sem contar com a Escola formal e, frequentemente, com recurso a didáticas locais edificadas numa vontade resistente de aprender aquilo que era necessário para, ali, viver: o trabalho, a natureza, a família, a cultura, as tradições, a religião.

Uma conversa acerca da Educação destes Adultos, nestes territórios, não se pode iniciar pelas palavras que nascem da ausência da educação escolar que, ali, nunca esteve disponível, para muitas daquelas pessoas. Pelo contrário, devemos começar essa conversa, partindo da educação que, ali, sempre existiu: a educação que essas pessoas construíram, nos seus territórios e redes comunitárias de vizinhança, nos contextos informais do trabalho, naquelas escolas que existiram sempre fora da escola oficial. Foi neste universo educacional, de matriz popular e raiz profundamente comunitária, que se formaram muitos dos que não usufruíram da educação formal e escolar que, quase sempre, os ignorou.

Conhecer, compreender, respeitar, valorizar e divulgar os conhecimentos e didáticas locais - de matriz popular e comunitária e presentes nos territórios do interior português - é conhecer um universo educativo plural, rico e inclusivo, frequentado e assumido por muitos milhares de portugueses que, sendo analfabetos literais ou funcionais, ou possuindo baixos níveis de escolarização, construíram uma Escola que serviu gerações e proporcionou, a milhares de concidadãos, o único acesso a processos estruturados de aprendizagem. 
Neste contexto, qualquer abordagem de Educação para estes adultos não deve deixar para trás qualquer fragmento deste universo educacional edificado em cada contexto territorial e comunitário e transmitido, de geração em geração, até ao presente.

Para a adequada concretização deste princípio básico da Educação de Adultos e considerando o contexto territorial no qual temos desenvolvido a nossa atividade - o Alentejo -, importa apresentar, de forma breve, alguns das coordenadas do que tem sido a evolução recente desta realidade nas regiões do interior, nomeadamente no Alentejo.

\section{A COORDENADA POLÍTICA}

\subsection{A realidade menos visível}

Em todo o território português, o universo associativo sempre foi uma das mais presentes e dinâmicas redes de participação cívica e social e um dos mais disponíveis e significativos contextos educadores para a população, em particular nos meios com menos presença de instituições públicas e menos ação das redes de educação e formação formais.

A Educação de muitos adultos, naqueles contextos territoriais e sociais, passou muito pela sua presença e participação nas instituições da sociedade civil aí existentes, em áreas como a cultura, o recreio, o desporto, a educação, a religião, entre outras. Este universo institucional de perfil muito diverso - associações de distintas naturezas, Casas do Povo, academias de instrução e recreio, paróquias, grupos amadores de teatro, clubes desportivos ou pequenas empresas locais - constituiu (e constitui) uma rede muito próxima das pessoas, em cada território, e serviu (e serve), quase sempre, de oportunidade alternativa para o acesso a processos estruturados de aprendizagem, nas áreas em que inscreve a sua atividade.

Esta realidade institucional e consequente ação educadora existiu sempre fora dos perímetros da rede escolar formal, dos recursos financeiros do estado e das agendas nacional e internacional que determinam o rumo das políticas de educação. No entanto, apesar desta periferia política e orçamental e do caráter inorgânico das redes que configuram, estas instituições, pelas suas dinâmica e resiliência, foram sempre promotoras de fortes dinâmicas territoriais, geradoras de lideranças locais e impulso de realização profissional e pessoal para muitos indivíduos. 
Nas últimas décadas, em três momentos distintos, tivemos a oportunidade de conhecer uma parte deste universo institucional e do respetivo potencial educativo:

i) em 1978, uma iniciativa da Direção-Geral de Educação Permanente do Ministério da Educação, liderada por Alberto Melo, através da qual, foi promovida uma política de «recenseamento voluntário» das iniciativas de educação não formal de base territorial, 0 que permitiu a desocultação de muitas iniciativas locais que promoviam contextos educadores, através de ambientes não formais de aprendizagem (Melo \& Benavente, 1978). A Educação de Adultos é, aqui, um instrumento para a "aprendizagem política e a coesão social e cultural de um país" (Melo, 1997:51).

ii) A Agência Nacional de Educação e Formação de Adultos (ANEFA) criada em 1999 e, também, dirigida por Alberto Melo, promove uma iniciativa através da qual estimula a candidatura de instituições ao prémio «Prémio Saber+». Dessa iniciativa, resultou a identificação e caracterização de centenas de projetos locais com uma forte dimensão educadora, quase sempre ancorados nas instituições da sociedade civil e participados por muitos milhares de pessoas (Trigo, 2001; Leitão \& Gonçalves, 2002).

iii) desde o início da atividade dos Centros de Reconhecimento, Validação e Certificação de Competências/CRVCC (em 2000) que o processo RVCC, ancorado na realização de um balanço de competências e elaboração consequente de um portefólio individual, evidenciou o papel estruturante do universo de instituições da sociedade civil presentes nos territórios, na construção e desenvolvimento de contextos educadores nos quais as pessoas concretizaram processos estruturados de aprendizagem, nas mais diversas áreas das suas vidas. Essas aprendizagens, pela sua relevância vital e pelas características que evidenciavam, quando avaliadas com base em referenciais que as comparavam com os conhecimentos e competências de natureza escolar e formal, foram (e são) objeto de reconhecimento, validação e consequente certificação formal, num processo que, pela primeira vez, criou um mecanismo de identificação, valorização e consideração escolar e/ou profissional do universo de aprendizagens concretizado nas instituições não escolares.

Todo este universo institucional, apesar da relevância que sempre assumiu na educação das pessoas, nos contextos territoriais em que desenvolveu a sua ação, manteve-se pouco 
visível e esteve quase sempre ausente das decisões e dos processos de concretização das políticas educativas, em particular no que respeita à população adulta.

\subsection{A realidade mais visível}

Com a entrada de Portugal, na Comunidade Económica Europeia/CEE (atual União Europeia), iniciou-se um processo, gradual e sistemático, de desenho e concretização de políticas de educação e formação de adultos, alicerçado nos distintos quadros de apoio ao desenvolvimento do país e respetivos dispositivos financeiros. Privilegiando, em grande medida, as regiões portuguesas menos desenvolvidas, nomeadamente do interior do país, estas políticas foram promovidas no âmbito de setores tão diversos como o apoio ao desenvolvimento do mundo rural, a promoção e modernização da economia, a qualificação profissional de ativos (empregados e desempregados) ou o próprio sistema educativo, em determinados segmentos mais diferenciados.

Esta nova realidade originou um novo universo de atores locais e mobilizou outros que, até então, se encontravam afastados destes territórios e destas áreas de educação e formação: associações de desenvolvimento local/ADL, empresas de formação, escolas profissionais públicas e privadas, centros de formação do Instituto do Emprego e Formação Profissional/IEFP, algumas autarquias locais, fundações e outras instituições equivalentes. Neste contexto, as escolas aparecem, num momento posterior, nomeadamente aquando da criação e promoção da Iniciativa Novas Oportunidades (2005), aproveitando, dessa forma, os recursos financeiros disponíveis para promoverem algumas das medidas políticas da área da educação e formação de adultos (e de jovens, pois coexistiam os dois eixos de intervenção) e alguma da sua oferta formativa de perfil mais vocacional e profissionalizante.

Desenvolvendo a sua ação quase sempre no interior do perímetro orçamental determinado pelos quadros europeus de apoio e constituídas, geralmente, por indivíduos muito qualificados, académica e tecnicamente, estas instituições assumiram, em muito pouco tempo, um forte protagonismo social e político nos territórios e lideraram, desde então, os principais impulsos de investimento e consequente desenvolvimento económico e social que aqueles recursos financeiros possibilitaram. Com esta coordenada social, esta nova realidade institucional tornou-se muito visível, organizada, eficaz na captação e execução de recursos, 
mobilizadora de dinâmicas territoriais, influenciadora de agendas políticas locais e nacionais e geradora de futuros líderes políticos, com influência em diversos níveis das comunidades locais.

Foi neste ambiente institucional e financeiro que foram sendo geradas, concretizadas e avaliadas, as, mais recentes e visíveis, políticas de educação e formação de adultos nos territórios do interior de Portugal, até à atualidade.

\subsection{0 diálogo entre as duas realidades}

Nesta coordenada política, na qual as duas realidades institucionais anteriormente descritas desenvolveram a sua atividade, verificou-se uma coexistência pacífica, mas pouco cooperativa. Na realidade, a nova dimensão criada pelas políticas de base europeia criou uma dinâmica territorial que se sobrepôs às dinâmicas já aí existentes e com elas conviveu sem grandes benefícios mútuos.

Nesta neutra convivência, assistiu-se à existência simultânea de dois dispositivos territoriais de educação e formação de adultos:

i) o primeiro, e mais antigo, determinado pelas instituições da sociedade civil dos territórios, concretizado em torno das atividades culturais, recreativas, desportivas e cívicas mais alicerçadas nos quotidianos das comunidades e financiado de forma casuística, com recursos endógenos, sempre escassos e imprevisíveis;

ii) o segundo, e mais recente, resultante da ação das novas instituições resultantes do novo quadro de desenvolvimento promovido pelas políticas internacionais e nacionais, suportado pelos respetivos quadros financeiros e concretizado a partir dos eixos dos programas europeus plurianuais de apoio ao desenvolvimento.

\section{A COORDENADA DIDÁTICA}

\subsection{As didáticas do território}

A rede territorial de instituições, suportada e liderada nas comunidades, ancorada nos saberes endógenos e promotora das aprendizagens a eles associadas criou, de forma 
sustentada, determinadas didáticas que se foram edificando e depurando ao longo do tempo e se transmitiram e fortaleceram, entre as gerações que se sucederam em cada contexto local.

Foi neste, rico e dinâmico, contexto social que se foram consolidando autênticas escolas de base comunitária, em áreas diversas, promovendo uma educação não formal de perfil intergeracional e popular:

i) as Escolas de Música das Bandas Filarmónicas, nas quais jovens e adultos convivem em torno de uma atividade cultural de grande implantação em todos os territórios, com um importante papel na identidade comunitária e promotora de muitos projetos de vida, em particular na dimensão profissional;

ii) os grupos desportivos, promotores da prática desportiva local, em alguns casos no âmbito dos jogos tradicionais, permitindo, dessa forma, a sua salvaguarda e divulgação;

iii) os grupos amadores de teatro, através dos quais muitas pessoas puderam participar culturalmente, de forma ativa, aí desenvolvendo conhecimentos e competências de comunicação e expressão, num contexto em que a leitura era uma rotina e o contacto com alguns dos mais clássicos autores uma necessidade;

iv) as paróquias, no seio das quais, se desenvolveu uma ampla atividade educadora decorrente da sua ação religiosa e em dimensões do quotidiano, tais como o casamento, a família, o desenvolvimento moral, entre outros aspetos relevantes para a vida comunitária;

v) as comissões de festas, instituições informais e de duração, por vezes, limitada, mas com uma forte presença na vida das comunidades e com profundo efeito educador nos seus participantes, pelas responsabilidades aí assumidas, pelo estatuto delas decorrentes e pela liderança nelas desenvolvida;

vi) os ofícios tradicionais (carpinteiros, mecânicos, costureiras, alfaiates, barbeiros, cabeleireiras, abegães, pedreiros, cozinheiros/as, artesãos, agricultores, entre outros), no âmbito dos quais se estruturaram corredores de formação profissional onde os mestres transmitiram, aos aprendizes, os seus conhecimentos e experiências; 
vii) as Assembleias e Juntas de Freguesia, órgãos autárquicos da política dos territórios, nos quais se concretizou a participação de muitas pessoas e se formaram muitos dos líderes locais;

viii) as rádios locais, de génese mais recente, mas com forte papel nas dinâmicas dos territórios, pela sua ação na produção e divulgação de informação local e na promoção da cultura endógena.

Toda esta rede de diferentes espaços e tempos de aprendizagem constituíram, em cada território, a mais dinâmica rede de educação e foram o contexto educador com maior presença na vida da maior parte das pessoas aí residentes. Nessa rede de educação não formal, foram-se desenvolvendo formas muito particulares de criar e transmitir o conhecimento, nas quais as formas de ensinar e aprender se estruturaram com base nas características geográficas, económicas, sociais e humanas de cada circunstância particular, criando aquilo a que chamamos as didáticas do território.

\subsection{As didáticas pré-construídas}

Em paralelo com a realidade anterior, foi sendo construída uma nova realidade, a partir da adesão de Portugal à CEE. Na realidade e como já referimos, com o acesso do país aos quadros europeus de apoio ao desenvolvimento e concomitantes financiamentos, surgiu uma rede nacional e regional de novos atores institucionais que foi promovendo, de forma sistemática e organizada, um novo conjunto de oportunidades de educação em contextos formais, nos quais a certificação se assumiu como a grande finalidade.

Neste novo enquadramento político e educativo, tudo foi diferente, relativamente à realidade até aí existente:

i) os saberes elegíveis para a organização dos contextos educativos resultaram de pormenorizados processos de identificação e análise de necessidades, quase sempre de natureza profissional e assentando normalmente num quadro de défice de qualificações das populações locais e em grandes linhas de orientação das políticas europeias e nacionais; 
ii) os formadores associados a estas formações foram, normalmente, pessoas com conhecimentos especializados e diferentes dos saberes existentes, quase sempre oriundas do exterior dos territórios, neles se limitando a exercer a sua atividade, numa base profissional e burocrática;

iii) os formandos foram sinalizados a partir de determinados critérios pré-estabelecidos, determinando, quase sempre, públicos-alvo muito diferenciados: desempregados, indivíduos em situação de fragilidade social, jovens à procura do primeiro emprego, senhoras com baixas qualificações e outros grupos, sempre sinalizados com algum défice de qualquer atributo considerado necessário para os processos de desenvolvimento económico do território;

iv) o financiamento resultou de candidatura a programas específicos, com regras e procedimentos exigentes e num ambiente competitivo, no qual apenas algumas instituições com determinadas competências técnicas conseguiam atuar e ter sucesso;

v) o «pacote de formação» incluía um exigente processo de concretização e avaliação, com recurso a procedimentos sistemáticos de natureza burocrática, em particular nas dimensões contabilística, de avaliação da execução física e dos impactos da formação nas dinâmicas de desenvolvimento local;

vi) as redes de parceiros foram um relevante critério de financiamento, tendo-se estabelecido um quadro de cooperação interinstitucional de base territorial alargada entre estes novos operadores, numa organização que, quase sempre, ignorou as instituições anteriormente existentes e que lhes retirou a oportunidade de estarem presentes nos fluxos financeiros existentes.

Esta nova didática, mais técnica, financiada e formatada pela arquitetura das políticas europeias e nacional, instalou-se nos territórios, à prova das suas próprias dinâmicas e história (salvo algumas exceções), devido aos volumosos financiamentos que conseguiu trazer, ao rendimento que foi distribuindo localmente e às lideranças que foi promovendo. Neste contexto, foi-se desenvolvendo, em cada território (nomeadamente nos do interior do país), um novo universo educativo que, até ao presente, se foi consolidando, apenas tendo sido perturbado pelas transições dos quadros europeus de financiamento. 


\section{A COORDENADA DOS SABERES}

\subsection{A valorização dos saberes endógenos}

As didáticas locais, assentando na valorização e divulgação do património local, sempre privilegiaram a aprendizagem dos saberes endógenos, muitos deles decorrentes das atividades cultural, económica e social de cada comunidade. 0 território, a natureza, o património material e imaterial, as profissões locais, os rituais e as tradições foram sempre os conteúdos privilegiados nos dispositivos comunitários de educação, nos quais se foi promovendo o encontro das diferentes gerações.

A passagem do legado cultural das gerações mais velhas para as mais jovens esteve sempre presente nos modelos educativos locais, transportando, até ao presente, muitos dos conhecimentos mais antigos e mais estruturantes de cada comunidade e da respetiva identidade.

\subsection{A valorização dos saberes exógenos}

As didáticas "pré-construídas» assentaram nas necessidades identificadas e consideradas instrumentais para o desenvolvimento, de acordo com os referenciais ditados pelos quadros políticos que as financiaram. As tecnologias da informação e comunicação, as competências profissionais diferenciadas e inexistentes nos territórios, as qualificações necessárias para o empreendedorismo e a competitividade, as línguas estrangeiras ou as questões relacionadas com as diferentes literacias, nas suas dimensões mais básicas e instrumentais, dominaram o quadro de conhecimentos a promover com as diferentes modalidades de formação desta nova realidade educativa.

Muito raramente, os saberes endógenos foram considerados no desenho e concretização de modalidades de formação, facto que os retirou do espectro de aprendizagens certificadas dos territórios. 


\section{A COORDENADA DAS PESSOAS QUE ENSINAM E QUE APRENDEM}

\subsection{0 encontro}

Nas abordagens mais territorializadas e comunitárias, o papel do conhecimento local, da experiência e da sapiência foi sempre muito valorizado e, consequentemente, as pessoas que os detinham, normalmente as mais velhas, foram sempre muito reconhecidas, valorizadas e respeitadas. Este facto fez com que a idade fosse uma variável de valorização dos indivíduos e que a intergeracionalidade assumisse uma dimensão estruturante nos processos educativos.

Os mestres das diferentes profissões, os vizinhos, os líderes locais, os professores das escolas, os párocos, os agentes da autoridade, os empresários locais, entre outros, foram, em muitos casos, as pessoas mais respeitadas das suas comunidades e os protagonistas centrais dos diferentes contextos educativos que se foram promovendo localmente.

Nestas circunstâncias, os processos educativos eram participados por todos, em todas as idades e em todas as áreas relevantes da vida de cada comunidade, normalmente em torno dos saberes estruturantes da identidade local. Um verdadeiro "encontro» de gerações e saberes, em cada território.

\subsection{0 desencontro}

Nas abordagens exógenas, sempre se privilegiaram os saberes mais formais, académicos e disciplinares e, consequentemente, as pessoas que os detinham foram as mais valorizadas, nos contextos em que aqueles eram promovidos. Atendendo ao perfil de qualificações formais existente na maioria dos territórios do interior português, assistiu-se, como já se referiu, à chegada de uma nova geração de pessoas de perfil mais qualificado, com um estilo de vida mais urbano e uma presença e ação mais burocráticas, nas comunidades.

As modalidades de formação desenvolvidas nestes contextos de qualificação certificada, pela natureza das mesmas, determinaram várias fraturas nas comunidades (Nico \& Nico, 2011):

i) a fratura dos saberes, determinada pela escolarização dos modelos e práticas de formação associados aos programas pré-formatados em que se encontravam ancorados, em oposição ao caráter menos formal e mais sistémico dos saberes de base local; 
ii) a fratura geracional, consequência da constituição dos grupos-alvo das formações, da perda de valor dos que possuíam os conhecimentos tradicionais e da emergência dos novos e mais instrumentais saberes e dos novos protagonistas. A separação das pessoas, através da sua sinalização específica, separou uns dos outros e criou bolsas humanas nas comunidades;

iii) a fratura social, promotora de exclusão e discriminação, em resultado da sinalização de necessidades de formação em determinados indivíduos, respetivo agrupamento e consequente encaminhamento para atividades de remediação, nas quais a educação assumiu um papel central, muitas vezes associado à atribuição de prestações sociais;

Destas três fraturas resultou um desencontro, cada vez mais evidente, nas comunidades, facto que fragilizou as estruturas locais de socialização e solidariedade e criou barreiras entre as pessoas e entre estas e as suas origens.

\section{A COORDENADA DO FUTURO}

Como tentámos demonstrar, nas últimas três décadas, em Portugal, nomeadamente nas regiões do interior do país, foram coexistindo dois universos educativos que, não se tendo ignorado, não cooperaram e não contribuíram, como deviam, para a coesão social e territorial.

Às dinâmicas educadoras territorializadas e de base comunitária que geraram didáticas locais que tanto contribuíram para o conhecimento, valorização e divulgação da cultura e do património locais, foram sendo sobrepostas novas dinâmicas desterritorializadas e desligadas dos contextos comunitários, geradas a partir dos quadros europeu e nacional de desenvolvimento e ancoradas em financiamentos significativos. $O$ diálogo entre estas duas realidades não se concretizou com a profundidade necessária nem com os benefícios desejáveis.

A Educação e Formação de Adultos em Portugal, nomeadamente nas regiões do interior, onde estas realidades são mais evidentes não deve desperdiçar qualquer contributo de ambos os universos. À riqueza cultural, institucional e humana do universo comunitário, dever-se-á adicionar o contributo dos contextos mais qualificados e qualificantes do segundo; ao conhecimento mais experiencial e empírico dos mestres dever-se-ão adicionar os conhecimentos mais científicos e tecnológicos dos jovens qualificados; ao financiamento local, frágil e 
imprevisivel deve adicionar-se o financiamento competitivo, mais robusto e previsível; a matriz singular e específica das aprendizagens locais deve enriquecer-se com o contributo mais disciplinar e padronizado das aprendizagens desterritorializadas; à certificação social deve juntar-se a certificação formal académica e/ou profissional.

Por outras palavras, na Educação e Formação dos Adultos, nada pode ficar para trás. Porque o que fica para trás é sempre a vida de cada pessoa. Se queremos que ninguém fique para trás, então nada da vida dessas pessoas e comunidades pode ficar para trás.

\section{Referências Bibliográficas}

LEITÃO, José \& GONÇALVES, Maria (Coords.) (2002). Guia dos Clubes S@bER+: princípios e

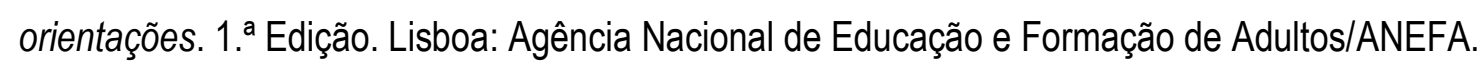

NICO, Bravo \& NICO, Lurdes (2011). Educação e Território: O (des)encontro geracional das aprendizagens e a fratura cultural no Alentejo. in Márcia de Alvarenga (org.). Educação de Jovens e Adultos. Em tempos e contextos de aprendizagem. Rio de Janeiro: Editora Rovelle. pp. 33-43/ (BN.CL.18)/ ISBN 978-85-61521-76-9/ / (http://hdl.handle.net/10174/2891 ) / (http://dx.doi.org/10.5935/978-85-61521-76-9.2016C016) /

MELO, Alberto \& BENAVENTE, Ana (1978). Educação Popular em Portugal (1974-1976). Lisboa: Livros Horizonte.

MELO, Alberto (1997). Educação de Adultos vista por Alberto Melo. In Revista Noesis. N. 43. Lisboa: Instituto de Inovação Educacional. Ministério da Educação.

TRIGO, Maria Márcia (2001). Ações de Curta Duração. In Revista Saber Mais. N. ${ }^{0} 11$. Lisboa: Agência Nacional de Educação e Formação de Adultos/ANEFA. 